\title{
Extended Fetal Bradycardia
} \author{
Emre Destegül'3, Gülnur Özakşid' \\ 1Department of Obstetrics and Gynecology, Kafkas University School of Medicine, Kars, Turkey \\ 2Department of Radiology, Kafkas University School of Medicine, Kars, Turkey \\ ${ }^{3}$ Clinic of Obstetrics and Gynecology, Kayseri Training and Research Hospital, Kayseri, Turkey
}

Servet Gençdal', Kahraman Ülker1', Murat Bozkurt', Melek Çiçek1, Yetkin Karasu', Duygu Kara Bozkurt², Levent Şahin',

\begin{abstract}
The purpose of this case report is to summarize a case of fetal sinus bradycardia resolving spontaneously. In this case report, we summarized a pregnant woman at $22^{\text {nd }}$ gestational week with fetal bradycardia. There was no medical history about fetal bradycardia. Physical examination was normal. Detailed fetal ultrasound examination and fetal echocardiography were also normal. There were no cardiac malformation and fetal hydrops. Fetal bradycardia was diagnosed by M-mode Doppler ultrasound. Heart beat was 78/min. The family was informed about the situation and followed conservatively. After 2 weeks of follow-up, fetal heart rate had returned to its normal pattern. She delivered at $39^{\text {th }}$ gestational week. Postpartum fetal physical and cardiac examinations were normal. The widespread use of fetal echocardiography in the diagnosis of fetal bradycardia among obstetricians would facilitate the determination of the type of fetal bradycardia. (JAREM 2015; 5: 139-41)
\end{abstract}

Keywords: Fetal sinus bradycardia, fetal echocardiography, ultrasonography

\section{INTRODUCTION}

American College of Obstetrics and Gynecology (ACOG) defines fetal bradycardia as fetal heart beat below 110/min (1). Fetal bradycardia constitutes almost $5 \%$ of all fetal arrhythmias (2). Causes of fetal bradycardia are vagal stimulation caused by umbilical cord compression, maternal hypotension, convulsion, and drug use. Because prolonged fetal bradycardia may cause fetal hypoxia and acidosis, the etiology of fetal bradycardia must be investigated carefully to prevent possible fetal morbidity and mortality. In this report, we summarized a case of prolonged fetal bradycardia that resolved spontaneously.

\section{CASE PRESENTATION}

A 22-year-old woman at $22^{\text {nd }}$ gestational week pregnancy was referred to our clinic with the diagnosis of fetal bradycardia. Her medical history was uneventful and she was not on a drug therapy. There was no cardiac anomaly or any kind of rhythm problem in her family. Second trimester screening was also normal. Ultrasound examination [GE Voluson Pro V (GE Healthcare, Tiefenbach, Austria) 4-7 MHz abdominal convex transducer] revealed a 21-week-old singleton gestation. Fetal examination was normal but fetal bradycardia was consisted (78/min). There were no cardiac malformations. Fetal bradycardia was verified with $\mathrm{M}$-mode and pulse Doppler ultrasound examinations (Figure 1, 2). On fetal echocardiography, four chamber views were normal; valvular and great vessel diameters were normal. No valvular regurgitation was noted, and venous flows (ductus venosus and inferior vena cava) were normal. The arterial duct as well as the foramen ovale were patent. The ratio of early to late-filling peaks showed no inversion at tricuspid and mitral valvular orifices, and the morphology was found to be normal with sustained bradycardia. Ventricles and atria were found to be synchronous; fetal heart rate was measured from atrial or ventricular $\mathrm{M}$-mode waveforms of five consecutive cardiac cycles, and it was also measured from the aortic or pulmonary valve Doppler waveforms of five consecutive cardiac cycles obtained during fetal quiescence that varied between 78 and 82 beats/ minute. All these findings indicated sinus bradycardia, and characteristic patterns of flow reversal are observed in the inferior vena cava in association with the premature beat of blocked atrial bigeminy; abnormal, early premature contractions may be observed on fetal M-mode. The patient's routine laboratory analysis and electrocardiography were also normal. Anticardiolipin antibody, antinuclear antibody, rheumatoid factor, and anti-Ro and anti-La antibody tests were also normal. The patient was followed conservatively. After one week of follow-up, the fetus still had bradycardia $(82 / \mathrm{min})$. Fetal heart rate was normalized at the $24^{\text {th }}$ week of pregnancy $(125 / \mathrm{min})$. She delivered at the $39^{\text {th }}$ gestational week with no complications. Postpartum fetal physical and cardiac examinations were normal. The patient gave an informed consent for the publishing of data.

\section{DISCUSSION}

Prolonged fetal bradycardia is a rare finding that can be observed during routine fetal ultrasound examination (2). These patients should be evaluated carefully with ultrasound and echocardiography in the aspect of cardiac malformations, fetal hydrops, atrioventricular relationship. Fetal echocardio- 


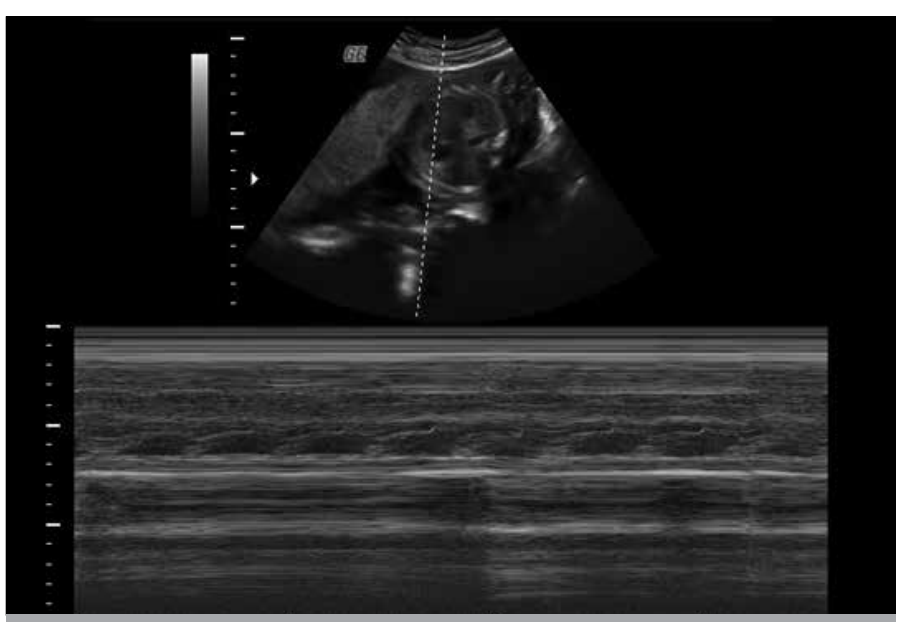

Figure 1. One-to-one ratio with M-Mode method atrioventricular conduction

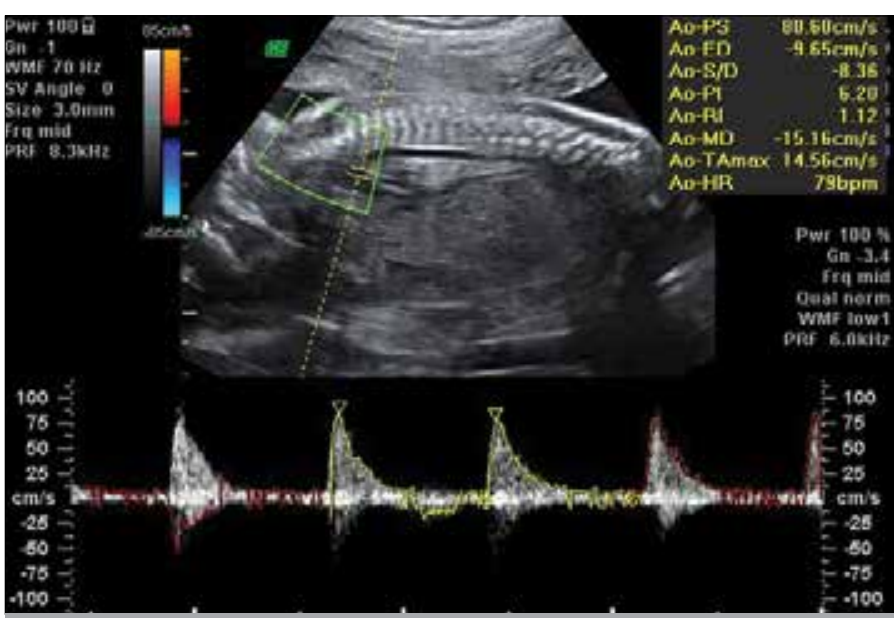

Figure 2. Pulse Doppler cardiac tracings obtained with the arcus aorta

graphic examination is crucial to evaluate fetal arrhythmias. Arrhythmias were diagnosed easily with M-mode Doppler ultrasound examination. Prolonged fetal bradycardia can be classified as follows: complete atrioventricular block (CAVB), sinus bradycardia, and bigeminy premature atrial block (3). CAVB is the most common cause of fetal bradycardia. Left atrial isomerism, atrioventricular canal defect or structurally corrected transposition exist in almost $50 \%$ of cases (4). CAVB should be excluded because its prognosis is bad. Collagen diseases, such as maternal systemic lupus, may cause either $1^{\text {st }}, 2^{\text {nd }}$, or $3^{\text {rd }}$ degree block or severe fetal bradycardia characterized with enlarged QRS complex (5). Serologic test results were normal in our patient. Our diagnosis was fetal sinus bradycardia because we did not observe any cardiac malformation, and atrioventricular relationship is completely normal. Usually, an etiological factor cannot be found in sinus bradycardia cases. Prolonged fetal bradycardia may develop because of maternal drug use, which can cause fetal stress, acidosis, hypoxia, and long QT and sick sinus syndromes (6). Reported cases in the literature showed that maternal hypothermia and hypoglycemia may also cause fetal bradycardia.
In these cases, heart rhythm resolves after the regulation of underlying reason (7). In our case, none of these reasons were observed. Fetal sinus bradycardia does not have a specific treatment and is not correlated with the hemodynamic instability of the fetus (8). This case was managed conservatively by only performing a close follow-up. After two weeks of fetal sinus bradycardia, it resolved spontaneously. If there is no sign of heart failure with coexisting bradycardia, vaginal delivery is the method of choice for terminating the pregnancy (9).

\section{CONCLUSION}

In this case, the patient delivered vaginally. In conclusion, the prognosis of prolonged fetal bradycardia depends on the underlying pathology. The widespread use of fetal echocardiography in the diagnosis of fetal bradycardia among obstetricians would facilitate the determination of the type of fetal bradycardia.

Informed Consent: Written informed consent was obtained from patient who participated in this case.

Peer-review: Externally peer-reviewed.

Author Contributions: Concept - M.B., S.G., K.Ü., M.Ç., Y.K., O.K.B., L.Ş., E.D., G.Ö.; Design - M.B., S.G., K.Ü., M.Ç., Y.K., O.K.B., E.D., G.Ö.; Supervision - M.B., S.G., K.Ü., M.Ç., Y.K., O.K.B., L.Ş., E.D., G.Ö.; Data Collection and/or Processing - M.B., S.G.; Analysis and/or Interpretation - M.B., S.G.; Literature Search - M.B., S.G.; Writing Manuscript - S.G., M.B.; Critical Review - M.B., S.G.

Conflict of Interest: No conflict of interest was declared by the authors.

Financial Disclosure: The authors declared that this study has received no financial support.

\section{REFERENCES}

1. ACOG Practice Bulletin No.106: Intrapartum fetalheart rate monitoring: nomeclature, interpretation, and general management guidelines. Obstet Gynecol 2009; 114: 192-202. [CrossRef]

2. Wladimiroff JW, Stewart PA, Tonge HM. Fetal bradyarrhytmia: diagnosis and outcome. Prenat Diagn 1988; 8: 53-7. [CrossRef]

3. Carvalho JS, Jaeggi E. Sustained fetal bradycardia: Mechanisms and pitfalls. Ultrasound Obstet Gynecol 2006; 28: 407. [CrossRef]

4. Buyton JP, Swersky SH, Fox HE, Bierman FZ, Winchester RJ. Intrauterine Therapy for presumptive fetal myocarditis with acquired heart block due to SLE. Arthritis Rheum 1987; 30: 44-9. [CrossRef]

5. Kalush F, Rimon E, Mozes E. Neonatal lupus erythematosus in offspring of mothers with experimental systemic lupus erytematosus. Am J Reprod Immunol 1992; 28: 264-8. [CrossRef]

6. Hofbeck M, Ulmer H, Beinder E, Sieber E, Singer H. Prenatal findings in patients with prolonged QT interval in the neonatal period. Heart 1997; 77: 198-204. [CrossRef]

7. Tanaka M, Ikeda T, Suzuki T, Yakubo K, Fukuiya T. A case of fetal bradycardia and sinusoidal like fetal heart rate pattern associated with maternal hypoglisemia. Fetal Diagn Ther 1995; 10: 207-9. [CrossRef] 
8. Baruteu $A E$, Schleich JM. Antenatal presentation of congenital long QT syndrome: A prenatal diagnosis not to be missed. Pediatr Cardiol 2008; 29: 1131-2. [CrossRef]
9. Friedman DM, Borg M, Rutkovsky L, Buyon JP. Bening fetal bradycardias diagnosed by echocardiography. Am J Perinatol 1995; 12 : 87-90. [CrossRef] 